\title{
The influence of extensive caving zones on the state and behavior of the surface as a result of underground mining works
}

\author{
Evgeny Fedorov ${ }^{1 *}$, Khaini-Kamal Kassymkanova, ${ }^{2}$ Gulnar Jangulova ${ }^{2}$, Natalia Miletenko ${ }^{l}$ \\ ${ }^{1}$ Institute of the Problems of Integrated Subsoil Development, 111020, Moscow, Russia \\ ${ }^{2}$ Al-Farabi Kazakh National University, 050046, Almaty, Kazakhstan
}

\begin{abstract}
The article discusses the features of the development of the Donskoy chromite deposit and the improvement of the applied development system with self-caving of ore. For a system with selfdestruction of ore, as well as for other similar systems, the weakest point is mining under the collapsed massif, which largely affects the stability of mine workings, their safety for the entire period of stope excavation, the effect of extensive zones of collapse on the state and behavior surface. This problem is one of the most important and urgent, especially with the transition of mining operations to deeper horizons, where the technological features of the mine field are significantly complicated. Therefore, the formation of extensive zones of collapsed rocks in the process of stope excavation leads to the development of negative processes for the formation of extremely high loads on the support of mine workings, and in certain geotechnical situations, the collapse zones affect the state of the day surface, where subsidence is possible up to the formation of craters. All this can lead to disastrous consequences, both in mine conditions and on the surface. The study of the formation of caving zones during the development of ore deposits is an urgent task.
\end{abstract}

Key words: geomechanics, development system, rock pressure, rock mass, chromite mining.

\section{Introduction}

The mining industry in Kazakhstan occupies one of the leading positions, the republic is among the 15 leading mining countries, and ranks second in the extraction of chromite ore, second only to South Africa [1-3].

The most indicative representatives of the widely using technologies of the caving system are the mining enterprises of the Donskoy Ore Mining and Processing Plant, which working out vast ore deposits of the field, fitted to the southern end of the Kempirsai massif, where more than 160 deposits, occurrences and chromite mineralization have been identified. At the same time, the overwhelming part of ore deposits, about $93 \%$, is mined underground. [4-6].

Statistical study of the structural disturbance of the massif involves the analysis of field data on the spatial orientation of cracks, their thickness, intensity, the presence of

\footnotetext{
*Corresponding author: evfedorov58@gmail.com
} 
filler, its characteristics and a number of other morphological features. The study and analysis of all these parameters was carried out mainly according to the data of the geological services of the mines, which in the process of driving mine workings carried out certification of the structural picture of the bottomhole space. Based on the results of processing the obtained structural data for areas and workings of various technological purposes, passed both in the rock and in the ore massif, a statistical analysis was carried out and the average values of the main parameters of fracturing were determined. The analysis of the spatial orientation of the cracks revealed four main systems with the following parameters.

I system; azimuth of extension $\alpha=90-120^{\circ}$, the angle of incidence of cracks in this system varies from 25 to $90^{\circ}$, mostly it is $\delta=70-80^{\circ}$, somewhat less often $\delta=60-70^{\circ}$.

II system; azimuth of extension $\alpha=290-350^{\circ}$, the cracks descent range is the widest: from 25 to $90^{\circ}$, more than $80 \%$ cracks have drop $\delta=70-80^{\circ}$.

III cracks system; azimuth of extension $\alpha=330-350^{\circ}, \mathrm{y}$ the angle of incidence of cracks in this system varies $0-90^{\circ}$, predominant descent $\delta=70-80^{\circ}$, cracks with an angle of incidence are quite common $\delta=50-70^{\circ}$, less often vertical.

IV system; azimuth of extension $\alpha=180-220^{\circ}$, the angle of incidence is within $\delta=$ $25-90^{\circ}$, более $80 \%$ cracks have descent $\delta=60-70^{\circ}$, less $\delta=80-90^{\circ}$. This system is most pronounced.

Analyzing the data obtained, it can be noted that fractures with different dip angles, from almost horizontal to vertical, occur in the studied areas of the field. However, most are steeply dropping cracks with inclination angles $\delta=70^{\circ}(20,0 \%), \delta=80^{\circ}(17,0 \%)$ and $\delta=75^{\circ}$ $(15,0 \%)$. Cracks are common with value $\delta=45^{0}(13,0 \%)$. Gentle cracks with $\delta=5-20^{\circ}$ the most rare and together account for $1-2 \%$ of the total number of investigated cracks.

Along with the spatial orientation of the cracks, an analysis of their intensity $J$ and thickness $m$ was carried out. The results obtained for different sections of the mine field give a spread of the $J$ index from 5 to 13 units per linear meter, and in terms of the thickness $m$ from 0.1 to $1.4-1.5 \mathrm{~cm}$. According to the genetic classification, these data refer to the so-called secondary cracks that break the rock mass into separate structural blocks and have a major impact on the strength and deformation properties of the rock mass. Within the structural blocks, primary microcracks are observed, characterized by high intensity within the range $\mathrm{J}=20-40$ pcs. on $\mathrm{rm}$. meter and low power, less than one millimeter. In tectonic zones, the thickness of the cracks reaches $m=3.0-5.0 \mathrm{~cm}$, and in some areas, the massif is completely fragmented and is a loose surroundings.

Therefore, it becomes necessary to reveal the nature of these complications and, on the basis of the revealed patterns of geomechanical processes accompanying mining, reasonably select rational technological development schemes, determine their parameters in order to exclude man-made catastrophic situations and ensure rational subsoil use.

\section{Materials and methods}

The system of mining with self-collapse of ore at the Donskoy Ore Mining and Processing Plant is applicable mainly in rocks of medium and low stability, which fully applies to the deposits of Don chromites, a characteristic feature of which is a high structural disturbance of the massif, the presence of various systems of cracks with different morphology, thickness, intensity and spatial orientation. All of this ultimately determines the low strength of both ore bodies and host rock mass. In this regard, one of the main and most urgent issues in the underground mining of chromite ore deposits is to ensure the stability and reliability of the operation of preparatory and grooved mine workings for the entire service life. 
The ores of the Kempirsay deposit are classified as easy to concentrate, there are two types according to the technological grade of ores [7]: rich with more than $45 \% \mathrm{Cr} 2 \mathrm{O} 3$, less - ordinary. The extraction of raw ore is carried out by underground methods $(94.1 \%)$ by the Molodezhnaya mine and the 10th anniversary of Kazakhstan's independence (DNA), as well as by the open pit (5.9\%) - by the «Yuzhny» open pit.

Underground mining of chrome ore is carried out by a self-caving system (Figure 1), belonging to the second class of the mining system according to the classification of Professor V.R. Imenitova.

This system of mining with self-caving of ore is characterized by the gradual separation of the ore mass from the massif without forced blasting under the influence of its own weight and rock pressure [8]. In the lower part of the block, under the collapsed ore massif, a network of outlet workings is carried out, separated by small pillars, a horizontal outcrop is created above the outlet horizon by an explosion - a jogging, on which, under the influence of its own weight and the pressure of overlying rocks, the massif collapses by cracking it under fractured conditions of unstable ores.

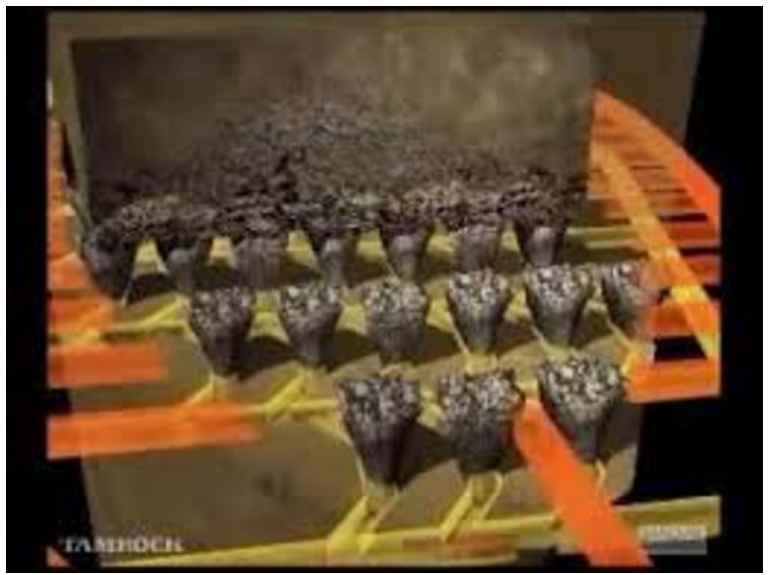

Fig.1. Development of reserves of the Don chromite deposit with a self-destruction system

To consider the methodological calculation scheme, the development of a powerful ore body O.b 2 in two stages is considered. For this purpose, the ore body is conditionally divided into two approximately equal parts - upper and lower. In this case, the height of the treatment chambers in both cases will be equal, i.e. $h_{l . c}=h_{u . c}$. Above the ore body R.b 2, the ore body O.b 1 was mined at an early stage, as a result of which a vast zone of collapsed rocks was formed. The height of the inter-ore space in real conditions can take on different values, we will designate this parameter $h_{i . o}$. This is shown schematically in Figure 1.

During the development of the first stage of the ore body R.b 2 above its lower part, by analogy with the ore body O.b 1, a zone of collapsed rocks of the corresponding height will form. Thus, the development of the lower part of the O.b 2 will be carried out under a multi-layer massif with layers of different thickness and geotechnical parameters, in particular, the coefficient of loosening $k_{l}[12]$. 


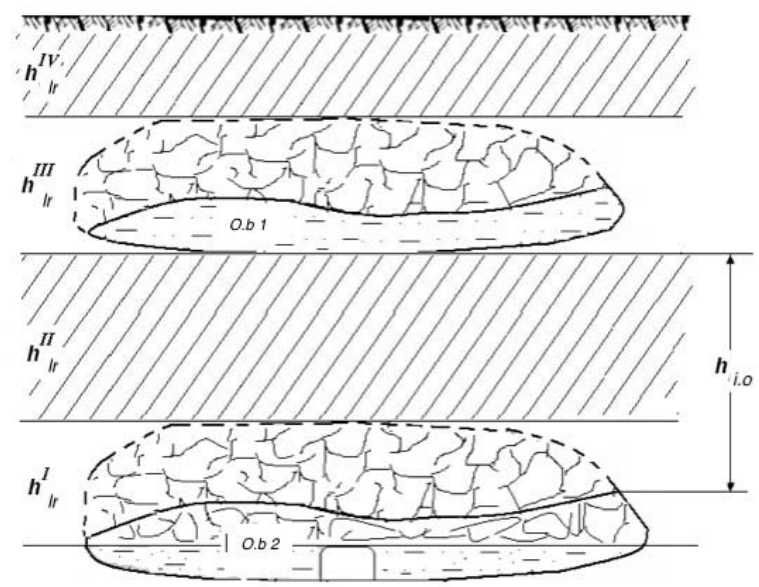

Fig. 2. Scheme for calculating the formation of a caving zone during the development of an ore deposit under a previously mined ore massif

The result is a collapse vault $h_{v}$, defined by the equation

$$
h_{v}=h_{l r}^{\prime}+h_{l r}^{\prime \prime}+h_{l r}^{\prime \prime \prime}+\ldots+h_{\mathrm{v}}^{\mathrm{i}},
$$

where

$$
h_{\mathrm{v}}^{\mathrm{i}}=\frac{h_{c}-\left[h_{l r}^{I}\left(k_{l}^{I}-1\right)+h_{l r}^{I I}\left(k_{l}^{I I}-1\right)+h_{l r}^{I I I}\left(k_{l}^{I I I}-1\right)+\ldots+h_{l r}^{i-1}\left(k_{l}^{i-1}-1\right)\right]}{k_{l}^{i}-1} ;
$$

The total height of the collapsed rocks

$$
h_{\text {об }}=h_{v}+h_{\kappa}
$$

With a large number of layers in the overpressing thickness, equation (2) is solved if the condition

$$
h_{c} \geq \sum_{n=1}^{i-I} h_{l r 1}\left(k_{o . f .}-1\right),
$$

where $n$-number of layers involved in collapse.

Looseness coefficient values $k_{p}$ layers of collapsed and compacted rocks are found by solving the equation $k_{l}^{i}=\frac{k_{o . m,}}{k_{s l}^{i}}$,

where $k_{s l}^{\mathrm{i}}$ is determined by the equation

Height of the inter-ore layer $h_{l r}^{I I}$ equally $h_{l r}^{I I}=h_{i . o}-\left(h_{l r}^{\prime}-h_{\mathrm{K}}^{\prime}\right)$

\section{Results and Discussion}

For clarity and description of the sequence of operations in determining the limiting vault of overlapping rocks during the development of treatment chambers under a multilayer array, the methodology is presented as a numerical example of the calculation. The considered calculation option is schematically shown in Figure 3. 


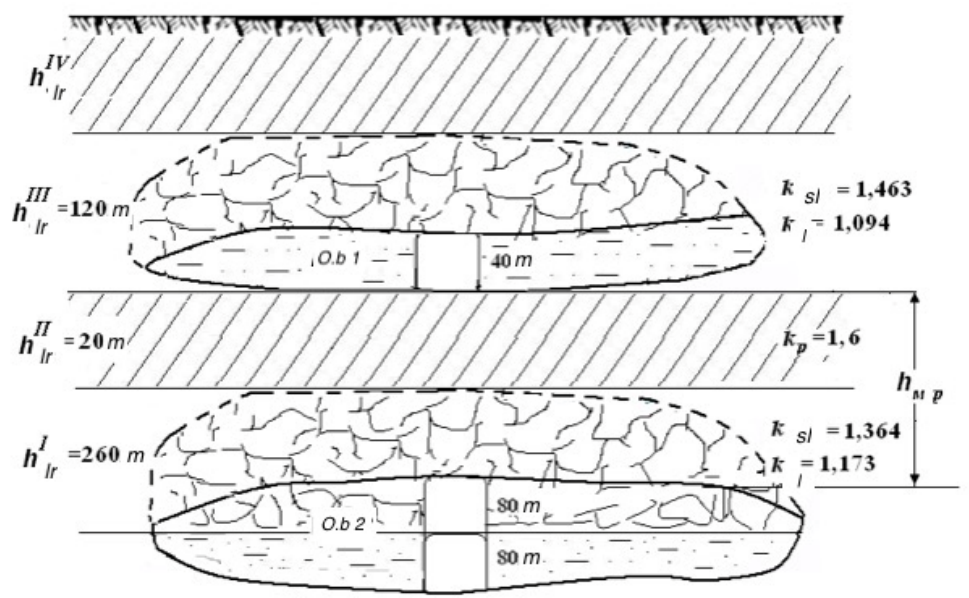

Fig.3. Scheme for calculating the limiting roof of collapse under a multilayer array

A heavy ore body O.b 2 of the second stage is being mined, i.e. its lower half. Mine chamber height $h_{l . c}=80 \mathrm{~m}$. As a result of the development of the upper half of the O.b 2, where the height of the mine chamber was $h_{u . c .}=80 \mathrm{~m}$, a layer of collapsed rocks has formed $h_{l r}^{1}$. Height $h_{l r}^{1}$ is $h_{s l . l r}^{I}=1,9785 h_{c}^{1,1149}=260 \mathrm{~m}$

Next, we find the geotechnical parameters of the layer $h_{l r}^{1}$. Compaction coefficient value $k^{l}{ }_{s l}$ is found according to [13]

$$
k^{l} s l=1,553 e^{-0,0005 h^{\prime} \cdot s l}=1,364
$$

Loosening coefficient of a layer of collapsed and compacted rocks $h_{1 r}^{1}$ takes on the meaning

$$
k_{l}^{l}=\frac{k_{r m}}{k_{s l}^{I}}=\frac{k_{r m}}{1,553 e^{-0,0005 h_{s l . l r}^{\prime}}}=1,173
$$

Layer $h_{l r}^{I I}$ represented by an intact massif with a loosening coefficient $k_{l}=1,6$. The layer thickness for the calculation is taken to be $h_{l r}^{I I}=20 \mathrm{~m}$, which corresponds to the size of the inter-ore space $h_{i . o}=200 \mathrm{~m}$.

Layer $h_{l r}^{I I I}$ formed during the development of an ore body R.b 1 with a thickness within $m=40 \mathrm{~m}$, i.e. with the size of the backing chamber $h_{c}=40 \mathrm{~m}$. Basic geotechnical parameters for $h_{l r}^{I I I}$ are found by analogy with the layer $h_{l r}^{I}$. As a result, we have: $h_{\mathrm{lr}}^{\amalg}=120$ м; $\mathrm{k}_{\mathrm{sl}}^{\mathrm{III}}=1,463 ; \mathrm{k}_{1}^{\mathrm{III}}=1,094$.

Having determined the basic initial data, we find the value of the collapse arch in the process of mining the lower half of the ore body O.b 2 by chambers $h_{c}=80 \mathrm{~m}$, using relations (1 and 2), as a result we have

$$
h_{\mathrm{v}}^{I V}=\frac{h_{c}-\left[h_{l r}^{I}\left(k_{l}^{I}-1\right)+h_{l r}^{I I}\left(k_{p}^{I I}-1\right)+h_{l r}^{I I I}\left(k_{l}^{I I I}-1\right)\right]}{k_{l}^{I V}-1}=20,0 \mathrm{~m}
$$

The height of the collapse vault will be $h_{v . d}=h_{l r}^{I}+h_{l r}^{I I}+h_{l r}^{\prime I I I}+h_{\mathrm{v}}^{I V}=420 m$ 
Full height of the collapsed layer $h_{d}=h_{v . d}+h_{c}=500 \mathrm{~m}$

Further, using relation (2.2), we find the relative compaction D for a layer of collapsed rocks $h_{d}=500 \mathrm{~m}$

$$
\mathrm{D}=0,6828 h_{d}^{0,5636}-2,11=20,6 \%
$$

As a result of the compaction, a free space is formed (backing chamber $h_{\mathrm{kn}}$ ), defined by the relation

$$
h_{c . p}^{\prime}=h_{d} \cdot D=103 \mathrm{~m}
$$

It should be noted here that the solution of this problem is carried out in a discrete form, which allows step-by-step determination of the calculated parameters of the underbilling process.

For a backing chamber $h_{\text {c.p. }}^{\prime}$ find a layer of collapsed rocks $h_{d}^{\prime}$

$$
h_{d}^{\prime}=\frac{h_{c . p .}^{\prime}}{k_{o . m /}-1}+h_{c . p .}^{\prime}=275 \mathrm{~m}
$$

The total height of the collapsed rocks is $h_{\text {d.t. }}^{\prime}=h_{d}+h_{d}^{\prime}=775 \mathrm{~m}$

Relative compression for $h_{\text {d.t }}^{\prime}$ will be $D^{\prime}=26,9 \%$

Find a backing chamber $\quad h_{c . p}^{\prime \prime}$ and the collapse vault $h_{d}^{\prime \prime}$, which will have a value

$$
h_{c . p}^{\prime \prime}=h_{d . t .}^{\prime} \cdot\left(D^{\prime}-D\right)=49 m \quad h_{d}^{\prime \prime}=131 m \quad h_{d . t}^{\prime \prime}=h_{d . t}^{\prime}+h_{d}^{\prime \prime}=906 m
$$

Relative compression for $h_{\text {d.t. }}^{\prime \prime}=906 \mathrm{M}$ will be $D^{\prime /}=29,6 \%$

Further, according to a similar scheme $h_{\mathrm{c} . \mathrm{p}}^{\prime \prime \prime}=24 \mathrm{M}, \quad h_{\mathrm{d}}^{\prime \prime \prime}=64 m, \quad h_{\mathrm{d} . \mathrm{t}}^{\prime \prime \prime}=970 m$, $D^{\prime / I}=30,8 \% ; \quad h_{c . p}^{\mathrm{IV}}=12 m, \quad h_{\mathrm{d}}^{\mathrm{IV}}=32 m, \quad h_{\mathrm{d} . \mathrm{t}}^{\mathrm{IV}}=1002 m, \quad D^{I V}=31,4 \% \quad ; \quad h_{c . p}^{V}=6 \mathrm{~m}$ $h_{\mathrm{d}}^{\mathrm{V}}=16 \mathrm{~m}$

$h_{\mathrm{d}}^{\mathrm{V}}=16 \mathrm{~m}$ - the value is relatively small, which does not require further calculations of the chambers of the padding. [14]

Finally, the total height of collapsed and unconsolidated rocks will be equal to $1018 \mathrm{~m}$

As a result, we calculate the maximum height of collapsed and compacted rocks, which will be $695 \mathrm{~m}$.

\section{Conclusion}

Thus, when mining an ore deposit with a thickness of 160-170 m under a previously mined ore mass with a massiveness of about 40 meters, located above at a distance of $200 \mathrm{~m}$, the capacity of the collapsed rock zone will be, according to calculations, a value close to 695 $\mathrm{m}$.

The developed methodological scheme is the starting point for solving the problems of bridging during the development of treatment chambers under the collapsed massif. As noted above, this picture arises during the stage-by-stage mining of powerful ore deposits in two stages. At the first stage, as a result of cleaning work, a zone of collapsed, loosened rocks with a certain degree of compaction is formed in the overlying massif. At the second stage, mining operations are carried out under a layered massif, where the lower layer is represented by collapsed rocks, and the subsequent layers are intact massif with appropriate geotechnical characteristics. 
Analytical studies and calculations carried out provide predictive data on the behavior and condition of the day surface above the treatment area, which makes it possible to assess the possibility of man-made disasters, both in the process of mining an ore deposit and upon completion of mining operations.

\section{References}

1. Ibragim Edilbaev. Revival (1995-2005), (2004)

2. Instructions for calculating the strain on the support of mine workings in the conditions of the mines of the Donskoy mining and processing plant. (Karaganda. - 2002)

3. Leonid Zherebko, Lyazzat Shamganova, Gulnar Jangulova, 16thInternational multidisciplinary scientific geoconference. Exploration and mining. Mineral processing. Sgem 30 june - 6 july (2016)

4. Dosanbay Bekberenov, Gulnar Jangulova, International Scientific and Technical Conference "Problems and ways of innovative development of the mining and metallurgical industry", Tashkent 27-29 November (2014)

5. Ibragim Edilbaev, Marat Bitimbaev, Leonid Zherebko, Development of a collapse zone in an overlying massif during mining of ore deposits by a self-collapsing system at Donskoy chromite deposits. Scientific and technical support for mining. Collection of works of the Institute of Mining named after D.A. Kunaev, No. 68, part I. Almaty, (2004)

6. Kabden Nugmanov, Leonid Zherebko, Stressed state of the massif in the mining area, Scientific and technical support of mining production. Proceedings of the D.A. Kunaev Institute of Mining. Almaty, T. 65. (2004)

7. Dosanbay Bekbergenov, Ayan Toktarov, Proceedings of the branch "Institute of Mining named after D.A. Kunaev (volume 84, Almaty, 2013)

8. Evgeny Kuzmin, Uzbekova Self-collapse of ore in underground mining (Tutorial book. M. Publishing house of the Moscow Mining University, 2006)

9. Stefan Nadolski, Mike Samuels1, Bern Klein, Craig J.R. Hart, Minerals Engineering $121(2018)$

10. "Kazgiprotsvetmet", (Project volume 2, book 3, Ust-Kamenogorsk, 2003)

11. Rafiee, Ataei, Khaloo Kakaie, Jalali, Sereshki, International Journal of Rock Mechanics and Mining Sciences, 105 (2018)

12. L.N. Zherebko, G.K. Jangulova, L.M. Pivovarova, Scientific and technical support of mining production. Proceedings of the D.A. Kunaev Institute of Mining, 75, 18-21 (2008)

13. Forecast of the likelihood of man-made disasters from the standpoint of geomechanical processes in the rock mass during the development of ore deposits in difficult mining and geological conditions at great depths (Report on research work. Funds of the Institute of Mining named after D.A. Kunaev. Almaty, 2008)

14. Methods and means of ensuring the stability of mine workings during the development of powerful deposits of chromite ores under a collapsed massif by a self-collapsing system (Report on Scientific Research. Funds of the Institute of Mining named after D.A. Kunaev. Almaty, 2012)

15. K.N. Trubetskoy, M.A. Iofis, I.V. Miletenko, N.A. Miletenko, V.N. Odintsev, Fundamental problems of the formation of the technogenic geoenvironment (Yekaterinburg: Institute of Mining of the Ural Branch of the Russian Academy of Sciences, 2012), 23-28 (2018)

16. S.D. Viktorov, M.A. Iofis, V.N. Odintsev, Gornyi Zhurnal, 4 (2005) 